\title{
BMJ Open Kerala Atrial Fibrillation Registry: a prospective observational study on clinical characteristics, treatment pattern and outcome of atrial fibrillation in Kerala, India, cohort profile
}

Bahuleyan Charantharayil Gopalan, ${ }^{\oplus 1}$ Narayanan Namboodiri, ${ }^{2}$ Jabir Abdullakutty, ${ }^{3}$ Gregory YH Lip, ${ }^{4,5}$ Allumootil George Koshy, ${ }^{6}$ Venugopal Krishnan Nair, ${ }^{7}$ Shifas Babu, ${ }^{8}$ Shaffi Muhammed, ${ }^{9}$ Jinbert Lordson Azariah, ${ }^{10,11}$ Raju George, ${ }^{12}$ Ashokan Nambiar, ${ }^{13}$ Unni Govindan, ${ }^{14}$ Geevar Zachariah, ${ }^{15}$ Natarajan Kumaraswamy, ${ }^{16}$ Sajeev Chakanalil Govindan, ${ }^{17}$ Syam Natesan, ${ }^{18}$ Anil Roby, ${ }^{19}$ Krishnakumar Velayudhan Nair, ${ }^{20}$ Anand M Pillai, ${ }^{20}$ Rachel Daniel, ${ }^{21}$ Kerala AF Registry Investigators

To cite: Charantharayil Gopalan B, Namboodiri N, Abdullakutty J, et al. Kerala Atrial Fibrillation Registry: a prospective observational study on clinical characteristics, treatment pattern and outcome of atrial fibrillation in Kerala, India, cohort profile. BMJ Open 2019;9:e025901. doi:10.1136/ bmjopen-2018-025901

- Prepublication history and additional material for this paper are available online. To view these files, please visit the journal online (http://dx.doi. org/10.1136/bmjopen-2018025901).

Received 9 August 2018 Revised 7 May 2019 Accepted 3 July 2019

\section{Check for updates}

(C) Author(s) (or their employer(s)) 2019. Re-use permitted under CC BY-NC. No commercial re-use. See rights and permissions. Published by BMJ.

For numbered affiliations see end of article.

\section{Correspondence to} Dr Bahuleyan Charantharayil Gopalan;

bahuleyan2001@yahoo.co.uk

\section{ABSTRACT}

Purpose Limited published data exist on the clinical epidemiology of atrial fibrillation (AF) in South Asia including India. Most of the published data are from the Western countries and the Far East. The Kerala AF registry was initiated to collect systematic, prospective data on clinical characteristics, risk factors, treatment pattern and outcomes of consecutive AF patients who consulted cardiologists across the state of Kerala, India.

Participants All newly diagnosed and previously reported patients aged $\geq 18$ years with documented evidence of AF on ECG were included. Patients with transient AF due to infection, acute myocardial infarction, alcohol intoxication, metabolic abnormalities and AF seen in postoperative cases and critically ill patients with life expectancy less than 30 days were excluded.

Findings to date $A$ total of 3421 patients were recruited from 53 hospitals across Kerala from April 2016 to April 2017. There were $51 \%(n=1744)$ women. The median age of the cohort was 65 (IQR 56-74) years. Hypertension, diabetes mellitus and dyslipidaemia were present in $53.8 \%, 34.5 \%$ and $42.2 \%$ patients, respectively. Chronic kidney disease was observed in $46.6 \%$, coronary artery disease in $34.8 \%$ and heart failure (HF) in $26.5 \%$ of patients. Mean $\mathrm{CHA}_{2} \mathrm{DS}_{2}-\mathrm{VASc}$ score of the cohort was 2.9, and HAS-BLED score was 1.7. Detailed information of antithrombotic and antiarrhythmic drugs was collected at baseline and on follow-up. During 1-year follow-up, 443 deaths (12.9\%) occurred of which $332(9.7 \%)$ were cardiac death and $63(1.8 \%)$ were due to stroke. There were $578(16.8 \%)$ hospitalisations mainly due to acute coronary syndrome, arrythmias and HF.

Future plans Currently, this is the largest prospective study on AF patients from India, and the cohort will be followed for 5 years to observe the treatment patterns and clinical outcomes. The investigators encourage collaborations with national and international AF researchers.

\section{Strengths and limitations of this study}

- Currently the largest prospective cohort of atrial fibrillation (AF) patients from South Asia

- Fifty-three participating centres recruited patients from government hospitals, teaching institutions, private and corporate hospitals located both in urban and rural areas of Kerala state.

- The collected data included physical examination, electrocardiographic and echocardiographic findings, laboratory investigations of blood sample and follow-up outcomes.

- Although the study is limited to Kerala, results may provide an indication of future epidemiology of $\mathrm{AF}$ in India as Kerala is ahead of other states in epidemiological transition.

- However, these registry data may not reflect the true incidence or prevalence of $\mathrm{AF}$ in the state, since it is a hospital-based study.

Trial registration number CTRI/2017/10/010097.

\section{INTRODUCTION}

Atrial fibrillation (AF) is the most common cardiac arrhythmia seen in clinical practice, and it is an independent risk factor for death in men and women. ${ }^{1} \mathrm{AF}$ is associated with a fivefold increase in stroke risk and 25\%-30\% stroke seen in adults are associated with this arrhythmia. ${ }^{2}$ While AF is a global problem, much of the available epidemiological data are from the Western countries and the Far East. ${ }^{4}$ Limited published data 
exist on the clinical epidemiology of AF in South Asia (see online supplementary table 1 ).

Kerala, the southernmost state of India, is witnessing an increase in the burden of patients with AF due to increased longevity, higher prevalence of cardiovascular risk factors and comorbid conditions. ${ }^{56}$ However, the treatment and care offered to these patients is generally perceived to be suboptimal especially with regard to stroke prevention strategy. Vitamin K antagonists (eg, warfarin) are the commonly used oral anticoagulants, but monitoring of international normalised ratio (INR) is highly erratic, ${ }^{7}$ and often low target values (Internatioal normalized ratio (INR) $<2.0$ ) is accepted by the physicians. Nevertheless, there is lack of information on the existing treatment strategy as well as how it compares with the guideline recommended management of AF. ${ }^{8}$ The Kerala AF registry aims to provide systematic, prospective data on clinical characteristics, risk factors, treatment pattern and outcomes of consecutive AF patients who consulted cardiologists across Kerala. The registry was instituted under the auspices of Cardiological Society of India, Kerala Chapter (CSI-K).

\section{COHORT DESCRIPTION}

All newly and previously diagnosed patients aged $\geq 18$ years with documented evidence of AF on ECG were included in the study from April 2016 to April 2017. The study was initiated in April 2016, and 53 hospitals across the state of Kerala have contributed patients during the 1 year enrolment period. In order to get the best representative data from both rural and urban areas of the whole state, patients were recruited from government, private and corporate hospitals from different regions of Kerala. At each site, one investigator and a study coordinator handled the patient recruitment. Kerala state has an area of $38863 \mathrm{~km}^{2}$ and a population of 37.3 million. ${ }^{9}$ For better coordination of the study, Kerala was divided in to three zones: south, middle and north with 20 participating sites from south, 21 from middle and 12 from north zone (figure 1). The three zones had one zonal coordinator each, who supervised the study conduct at their respective zones.

Patients with transient AF due to causes like acute myocardial infarction, infection, alcohol intoxication, metabolic abnormalities, postoperative cases and critically ill patients with life expectancy less than 30 days were excluded. Each patient was enrolled in the registry after examination by the cardiologist(s) of the participating centre. Detailed medical history, physical examination and laboratory investigation including echocardiography was done, and the results were entered in the case report form (CRF).

Patients were classified into AF with valvular heart disease (AFVHD) and non-valvular AF (NVAF). AFVHD is defined as those cases associated with mitral stenosis, prosthetic valve implantation and

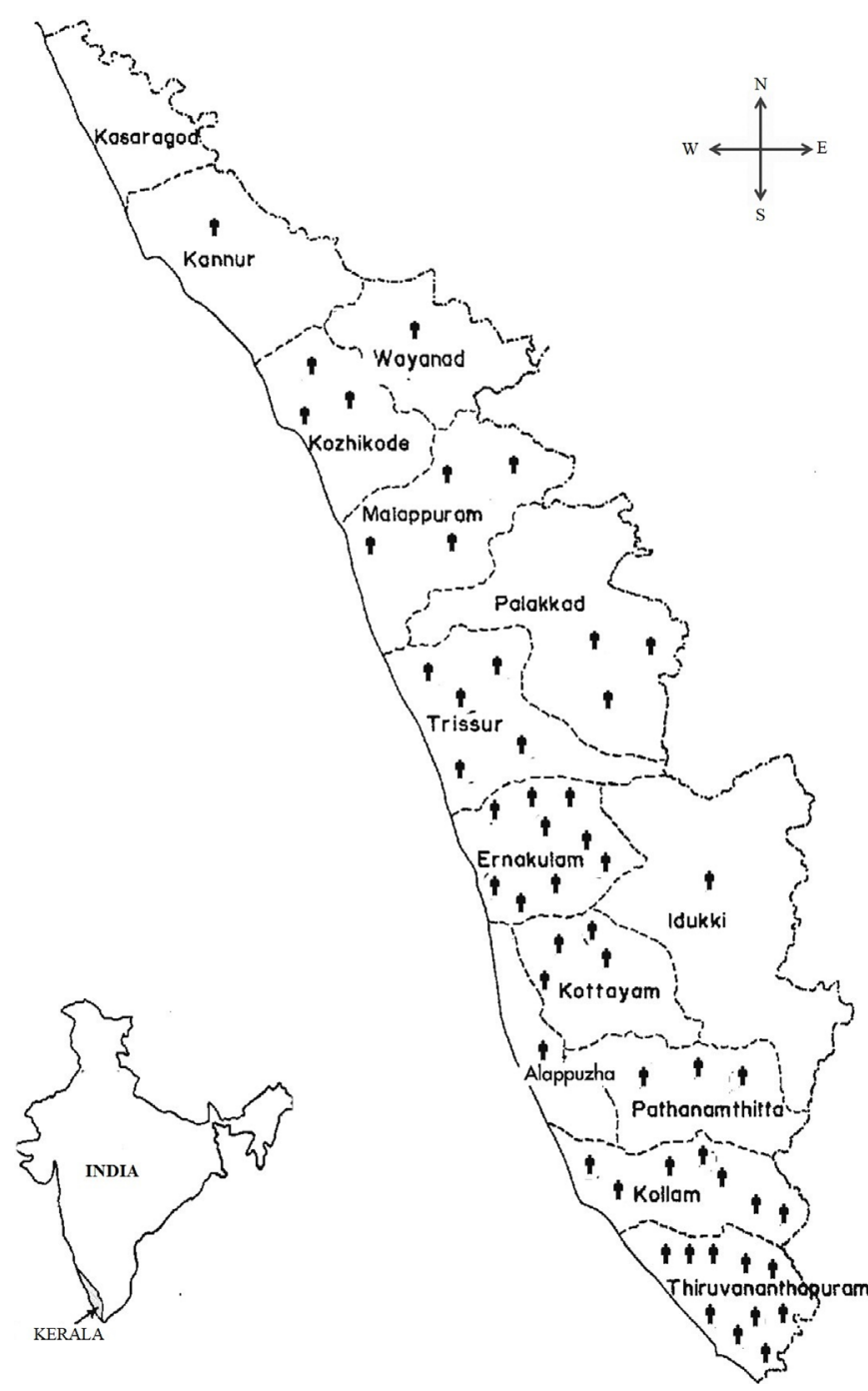

Figure 1 Map of Kerala showing the distribution of study sites.

mitral valve repair. These patients were further categorised as rheumatic or non-rheumatic and subcategorised as mitral, aortic or combined based on the clinical and echocardiographic findings. Out of the 914 AFVHD patients, $80.2 \%$ were rheumatic and $19.8 \%$ were non-rheumatic. The higher proportion of rheumatic aetiology seen in AFVHD patients could be due to the higher prevalence of rheumatic heart disease in Kerala. AF rhythm type was classified into paroxysmal, persistent and permanent. Stroke risk was estimated using the Congestive heart failure, Hypertension, Age $\geq 75$, Diabetes mellitus, Previous Stroke, Vascular disease, age 65 to 74 , Sex category $\left(\mathrm{CHA}_{2} \mathrm{DS}_{2}-\mathrm{VASc}\right)^{10}$ score and bleeding risk using the Hypertension, Abnormal renal/ liver function, stroke, bleeding history or predisposition, labile INR, Elderly age $>65$ years, Drugs/ alcohol (HAS-BLED) score. ${ }^{11}$ Detailed data on treatment, mainly stroke prophylaxis regimen, antiarrhythmic drug treatment, pacemaker implantation, AF ablation, surgery for AF and device closure of left atrial appendage and treatment 
for comorbidities, were collected at the time of recruitment and follow-up. Data on major outcomes including death (all-cause as well as cardiac) and need for hospitalisation were documented at 30 days, 6 months and 1 year. The cohort will be followed up annually for 5 years through clinic visit or by telephonic contact. Five-year follow-up will be completed by April 2022.

\section{Patient and public involvement}

Patients were not involved in the design of the study. Once the patients were recruited in the study, they were explained the health consequences of $\mathrm{AF}$ and the need for stroke prevention and arrhythmia management by the cardiologist.

\section{Statistical analysis}

Data were entered using EpiData Entry 3.1 version software $^{12}$ and analysed using $\mathrm{R}$ software ${ }^{13}$ and Microsoft Excel package.

\section{Findings to date}

A total of 3421 patients were recruited between 4 April 2016 and 3 April 2017. Follow-up at 30 days, 6 months and 1 year was completed by April 2018. NVAF constituted 73.3\% ( $\mathrm{n}=2507)$ and AFVHD 26.7\% ( $\mathrm{n}=914)$ of patients. There were $49 \% \quad(\mathrm{n}=1677)$ men and $51 \% \quad(\mathrm{n}=1744)$ women. The median age of the cohort at recruitment was 65 years (IQR 56-74). The median body mass index of the study population was $24.22 \mathrm{~kg} / \mathrm{m}^{2}$ (IQR 21.6-26.5). Patient characteristics and prevalence of risk profile of the cohort at the time of recruitment is given in table 1 . AFVHD was more common in women compared with men $(67.4 \%$ vs $32.6 \%)(\mathrm{p}<0.001)$, whereas NVAF was more common in men $(55 \%$ vs $45 \%)(\mathrm{p}<0.001)$. Hypertension, diabetes mellitus and dyslipidaemia were present in 53.8\% $(\mathrm{n}=1840), 34.5 \%(\mathrm{n}=1179)$ and $42.2 \%(\mathrm{n}=1443)$ cases of AF, respectively. History of rheumatic fever was present $17.7 \%(n=607)$ of patients. Chronic kidney disease (creatinine clearance below $60 \mathrm{~mL} / \mathrm{min})^{14}$ was observed in $46.6 \%(n=1597)$ of patients, coronary artery disease in

Table 1 Baseline characteristics at the time of recruitment by gender

\begin{tabular}{|c|c|c|c|}
\hline Parameters & $\begin{array}{l}\text { Men }(n=1677) \\
n(\%)\end{array}$ & $\begin{array}{l}\text { Women }(n=1744) \\
n(\%)\end{array}$ & $\begin{array}{l}\text { Total }(n=3421) \\
n(\%)\end{array}$ \\
\hline Age (in years) (median and IQR) & $65(56-74)$ & $65(56-74)$ & $65(56-74)$ \\
\hline Weight $(\mathrm{kg})($ mean $\pm S D)$ & $66.3( \pm 11)$ & $58.4( \pm 10.8)$ & $62.31( \pm 11.6)$ \\
\hline $\mathrm{CHA}_{2} \mathrm{DS}_{2}-\mathrm{VASc}$ score $($ mean $\pm \mathrm{SD})$ & $2.60( \pm 1.7)$ & $3.20( \pm 1.7)$ & $2.91( \pm 1.7)$ \\
\hline Hypertension & $936(55.8)$ & $904(51.8)$ & $1840(53.8)$ \\
\hline Diabetes & $611(36.5)$ & $568(32.5)$ & 1179 (34.5) \\
\hline Stroke/TIA or systemic embolism & $246(14.7)$ & $265(15.3)$ & $511(14.9)$ \\
\hline Coronary artery disease & $764(45.5)$ & $423(24.3)$ & 1187 (34.8) \\
\hline Respiratory disease & $371(22.8)$ & $343(19.7)$ & $714(17.7)$ \\
\hline Congenital heart disease & $37(2.3)$ & $43(2.5)$ & $80(2.4)$ \\
\hline Gastrointestinal bleed & $77(4.6)$ & $46(2.6)$ & $123(3.6)$ \\
\hline Thyroid disease & $228(13.6)$ & $357(20.5)$ & $585(17.1)$ \\
\hline NYHA Class I and II & 1375 (81.9) & $1443(82.6)$ & $2818(82.4)$ \\
\hline NYHA Class III and IV & $299(17.8)$ & $302(17.3)$ & $601(17.6)$ \\
\hline Paroxysmal AF & $706(42.1)$ & $643(36.8)$ & 1349 (39.4) \\
\hline Persistent AF & $261(15.5)$ & $230(13.1)$ & $491(14.4)$ \\
\hline
\end{tabular}

AF, atrial fibrillation; NYHA, New York Heart Association; TIA, transient ischaemic attack. 
Table 2 List of medication at baseline and first follow-up (30 days)

\begin{tabular}{|c|c|c|c|c|c|c|}
\hline & \multicolumn{3}{|c|}{ Medication at baseline } & \multicolumn{3}{|c|}{ Medication at first follow-up } \\
\hline & Men n (\%) & Women n (\%) & Total n (\%) & Men n (\%) & Women n (\%) & Total n (\%) \\
\hline Warfarin & $501(29.8)$ & $660(37.8)$ & 1161 (34) & $769(45.9)$ & $975(55.9)$ & $1744(50.9)$ \\
\hline Acitrom & $134(8.0)$ & $148(8.5)$ & $282(8.2)$ & $221(13.1)$ & 225 (12.9) & $446(13.1)$ \\
\hline Phenindione & $7(0.4)$ & $2(0.1)$ & $9(0.2)$ & $2(0.1)$ & $1(0.05)$ & $3(0.9)$ \\
\hline Dabigatran & $31(1.8)$ & $15(0.9)$ & $46(1.3)$ & $58(3.5)$ & $42(2.4)$ & $100(2.9)$ \\
\hline Apixaban & $11(0.7)$ & $7(0.40)$ & $18(0.5)$ & $38(2.3)$ & $19(1.1)$ & $57(1.6)$ \\
\hline Rivaroxaban & $3(0.17)$ & $1(0.06)$ & $4(0.1)$ & $21(1.2)$ & $13(0.74)$ & $34(1.0)$ \\
\hline ASA & $382(22.7)$ & 285 (16.1) & 667 (19.5) & $524(31.3)$ & 390 (22.3) & 914 (26.7) \\
\hline Clopidogrel & 334 (19.9) & $245(14.0)$ & 579 (16.9) & $517(30.8)$ & $411(23.5)$ & $928(27.1)$ \\
\hline Prasugrel & $2(0.1)$ & $3(0.17)$ & $5(0.14)$ & $2(0.1)$ & $3(0.2)$ & $5(0.1)$ \\
\hline Ticagrelor & $2(0.1)$ & $1(<0.1)$ & $3(0.1)$ & $9(0.5)$ & $2(0.1)$ & $11(0.3)$ \\
\hline Amiodarone & 138 (8.2) & $116(6.6)$ & $254(7.4)$ & $265(15.8)$ & $241(13.8)$ & 506 (14.8) \\
\hline Propafenone & $4(0.2)$ & $3(0.1)$ & $7(0.2)$ & $2(0.1)$ & $3(0.2)$ & $5(0.1)$ \\
\hline Flecainide & $8(0.5)$ & $9(0.5)$ & $17(0.5)$ & $6(0.4)$ & $10(0.6)$ & $16(0.4)$ \\
\hline Sotalol & $2(0.11)$ & 0 & $2(0.1)$ & $3(0.2)$ & 0 & $3(0.9)$ \\
\hline Beta blockers & 541 (32.2) & $519(29.7)$ & $1060(30.9)$ & $840(50.1)$ & 786 (45.0) & $1626(47.5)$ \\
\hline ACE inhibitors & $97(5.7)$ & 77 (4.4) & $174(5.1)$ & $163(9.7)$ & $116(6.6)$ & $279(8.1)$ \\
\hline ARB & 167 (9.9) & $246(14.1)$ & 413 (12.0) & $245(14.6)$ & $328(18.8)$ & $573(16.7)$ \\
\hline Digoxin & $296(17.6)$ & $466(26.3)$ & $762(22.2)$ & $424(25.2)$ & $621(35.6)$ & $1045(30.5)$ \\
\hline
\end{tabular}

ARB, angiotensin receptor blockers; ASA, acetyl salicylic acid (aspirin).

$34.8 \%(\mathrm{n}=1187)$ and heart failure in 26.5\% ( $\mathrm{n}=904)$ of patients. Mean $\mathrm{CHA}_{2}$ DS-VASc score of the cohort was 2.9, and HAS-BLED score was 1.7. Daily use of medication at baseline and at 1-month follow-up are reported in table 2. A total of $443(12.9 \%)$ deaths and $578(16.8 \%)$ hospitalisation occurred during 1-year follow-up (table 3). In all age groups, majority of hospitalisation and death occurred during the first half of follow-up period ( $61.8 \%$ and $62.3 \%$, respectively) than the second half (figures 2 and 3). In the Indian Heart Rhythm Society-Atrial Fibrillation registry, ${ }^{7}$ the mortality and the hospitalisation rates were $6.5 \%$ and $8 \%$, respectively. In the EURObservational Research Programme Atrial Fibrillation registry, ${ }^{15}$ 1-year mortality was $5.7 \%$.

Table 3 Death and hospitalisation at different time periods

\begin{tabular}{lcccc} 
Events & $\begin{array}{l}\text { Recruitment to } \\
\text { 1 month }\end{array}$ & $\mathbf{1 - 6}$ months & $\mathbf{6}$ months-1 year & Total in 1 year (\%) \\
\hline Death (all causes) & $\mathbf{6 9}$ & $\mathbf{2 0 7}$ & $\mathbf{1 6 7}$ & $\mathbf{4 4 3}(\mathbf{1 2 . 9 )}$ \\
\hline Cardiac & 54 & 157 & 121 & $332(9.7)$ \\
Stroke & 11 & 21 & 31 & $63(1.8)$ \\
Other & 4 & 29 & 16 & $49(1.4)$ \\
Hospitalisation (all causes) & $\mathbf{1 4 7}$ & $\mathbf{2 1 0}$ & $\mathbf{2 2 1}$ & $\mathbf{5 7 8 ( 1 6 . 9 )}$ \\
Stroke & 15 & 12 & 24 & $51(1.5)$ \\
Transient ischaemic attack & 3 & 3 & 6 & $12(0.4)$ \\
Acute coronary syndrome & 42 & 94 & 66 & $202(5.9)$ \\
Arrythmia & 29 & 56 & 90 & $175(5.1)$ \\
Heart failure & 34 & 23 & 17 & $74(2.2)$ \\
Systemic embolism other than stroke & 3 & 4 & 4 & $11(0.3)$ \\
Gastrointestinal bleed & 10 & 5 & 8 & $23(0.7)$ \\
Intracranial bleed & 1 & 4 & 2 & $7(0.2)$ \\
Minor bleed & 10 & 9 & 4 & $23(0.7)$ \\
\hline
\end{tabular}




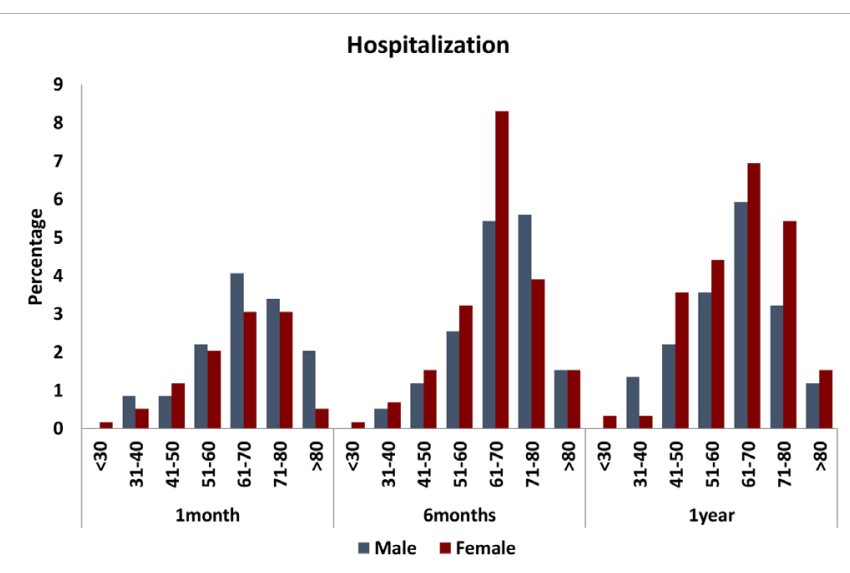

Figure 2 Incidence of hospitalisations among different age groups of male and female patients with AF.

\section{Comparison with other published AF cohorts}

Literature review showed three studies on patients with $\mathrm{AF}$ from South Asia, of which two are prospective cohort studies. The Indian Heart Rhythm Society-Atrial Fibrillation (IHRS$\mathrm{AF})^{7}$ registry, with 1537 patients from 12 cities across India was the only available study exclusively on Indian patients with $\mathrm{AF}$ with study sites predominantly from secondary or tertiary referral cardiac centres. Even though the multinational cross-sectional study, the Real-Life Global Survey Evaluating Patients with Atrial Fibrillation ${ }^{16}{ }^{17}$ had an Indian cohort of 301 patients, all were recruited from private healthcare institutions located in 15 urban areas. The Randomized Evaluation of Long-Term Anticoagulation Therapy ${ }^{18}$ was a prospective registry on patients with $\mathrm{AF}$ presenting to the emergency department in 46 countries including 2536 Indian patients from 22 hospitals in India. The Kerala AF Registry is the largest prospective cohort of patients with $\mathrm{AF}$ from India.

Unique aspects of the study include close collaboration of a wide range of contributing centres and systematic collection of outcome data. The registry recruited patients from government hospitals, teaching institutions, private and corporate hospitals

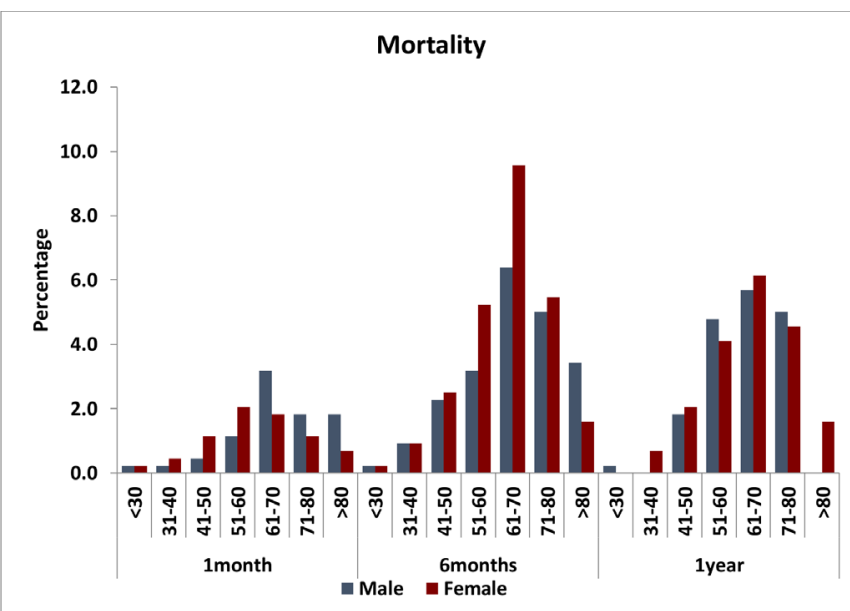

Figure 3 Incidence of mortality among different age groups of male and female patients with AF. located both in urban and rural areas of Kerala state. This has enabled the cohort to have patients from different socioeconomic backgrounds and lifestyle. Furthermore, many registries globally are sponsored by pharmaceutical or device companies, and the data collected may be influenced by the focus on patients with AF treated by their drugs or devices, leading to the possibility of selection bias. ${ }^{19}$ This study, however, has been sponsored by the professional association of cardiologists in the state, which is the CSI-K. Many published AF registries ${ }^{7}$ 16-24 (see online supplementary tables 1 and 2) have emphasised the need for adherence to the evidence-based treatment for reducing the stroke risk and overall mortality. Even though multiple AF databases are available from many countries that focus on various aspects of AF, there has been lack of coordination between these registries. An International Collaborative Partnership for the Study of Atrial Fibrillation, a worldwide partnership for investigators and countries has been initiated to capture all types of treatment patterns offered to the ever increasing population of patients with $\mathrm{AF}^{25}$ The global burden of AF is likely to grow in an epidemic proportion as observed by the World Heart Federation. ${ }^{26}$ Although this phenomenon is observed from high-income countries, ${ }^{27-29}$ the clinical observations indicate the signal for a steady increase in the burden of patients with AF in India too. ${ }^{30}$ Currently, the available data from India have been inadequate to provide exact prevalence, morbidity, mortality and standard of care of patients with AF. Furthermore, the existing studies reveal lower usage of oral anticoagulants for stroke prevention in patients with AF. India being a large country with interstate variations in terms of epidemiology of diseases and other health indicators, a state-wide collection and compilation of data seem to be the ideal way for generating national data. ${ }^{31}$ The Kerala AF registry was therefore initiated as a statewide collection of data on patients with AF who seek medical advice, which could provide more information about the clinical profile, sociodemographic characteristics and existing standard of treatment for patients with $\mathrm{AF}$ and how it differs from national and global data.

\section{Ethical considerations}

The study was conducted according to the ethical guidelines of Indian Council of Medical Research and as per the ethical principles specified in Declaration of Helsinki. Informed consent was taken from all participants. Data collected are held centrally in a secure data base and only deidentified information were used for analysis.

\section{Author affiliations}

${ }^{1}$ Department of Cardiology, Ananthapuri Hospitals and Research Institute, Thiruvananthapuram, India

${ }^{2}$ Department of Cardiology, Sree Chitra Tirunal Institute for Medical Sciences and Technology, Thiruvananthapuram, India 
${ }^{3}$ Cardiology, Lisie Heart Institute, Ernakulam, Kerala, India

${ }^{4}$ Liverpool Centre for Cardiovascular Science, University of Liverpool, United Kingdom, Liverpool, United Kingdom

${ }^{5}$ Aalborg Thrombosis Research Unit, Department of Clinical Medicine, Aalborg University, Aalborg, Denmark

${ }^{6}$ Department of Cardiology, Medical College Hospital, Trivandrum, India ${ }^{7}$ Department of Cardiology, Pushpagiri Medical College Hospital, Thiruvalla, India ${ }^{8}$ Cardiovascular Centre, Ananthapuri Hospitals and Research Institute, Thiruvananthapuram, India

${ }^{9}$ Ministry of Health, Public Health, Al Taif, Saudi Arabia

${ }^{10}$ Department of Clinical Research, Ananthapuri Hospitals and Research Institute,

Thiruvananthapuram, India

${ }^{11}$ Department of Research, Global Institute of Public Health, Trivandrum, India

${ }^{12}$ Department of Cardiology, Geovernment Medical College Hospital, Kottayam, India

${ }^{13}$ Department of Cardiology, Baby Memorial Hospital, Calicut, India

${ }^{14}$ Department of Cardiology, Jubilee Mission Hospital Trust, Thrissur, India

${ }^{15}$ Department of Cardiology, Mother Hospital, Thrissur, India

${ }^{16}$ Department of Cardiology, Amrita Institute of Medical Sciences and Research Centre, Cochin, India

${ }^{17}$ Department of Cardiology, Government Medical College Hospital, Calicut, India

${ }^{18}$ Department of Cardiology, Government General Hospital, Kollam, India

${ }^{19}$ Department of Cardiology, Dr. Damodaran Memorial Hospital, Kollam, India

${ }^{20}$ Cardiovascular Centre, Ananthapuri Hospitals and Research Institute,

Thiruvananthapuram, India

${ }^{21}$ Department of Cardiology, NS Memorial Institute of Medical Sciences, Kollam, India

Acknowledgements We would like to thank the Cardiological Society of India Kerala Chapter for supporting the study. Our sincere appreciation to Mr S Alex, Ms Priya Chembon, Dr Krishna Priya and Dr Uma Vasudevan (Ananthapuri Hospitals and Research Institute, Trivandrum) and Dr A Chitra Grace, Ms Minu Abraham and Dr G K Mini (Global Institute of Public Health, Trivandrum) for their help and assistance in the maintenance of the registry data.

Collaborators Cardiologists form government public hospitals, teaching institutions, private and corporate hospitals located both in urban and rural areas of Kerala state contributed towards the cohort. The group of investigators under the professional association Cardiological Society of India- Kerala Chapter, strongly encourages national and international collaborations. There is an urgent need for national data on $\mathrm{AF}$ representingall states. Interested researchers can contact $\mathrm{Dr}$. C G Bahuleyan at bahuleyan2001@yahoo.co.uk Kerala AF Registry Investigators: Charantharayil Gopalan Bahuleyan. MD, DM (AnanthapuriHospitals and Research Institute, Trivandrum); Narayanan Namboodiri. MD, DM(Sree Chitra Tirunal Institute for Medical Sciences and Technology, Trivandrum); Abdullakutty Jabir. MD, DM (Lisie Heart Institute, Ernakulam); Krishnana Nair Venugopal. MD, DM (PushpagiriMedical College, Thiruvalla); Raju George. MD, DM (Medical college Hospital,Kottayam); Govindan Unni. MD, DM (Jubilee Hrudhayalaya, Trichur); Geevar Zachariah. MD, DM (Mother Hospital, Trichur); K.U Natarajan. MD, DM (Amritalnstitute of Medical sciences, Kochi); N. Syam. MD, DM (District Hospital,Kollam); Anil Roby. MD, DM (Dr. Damodaran Memorial Hospital, Kollam); P.BJayagopal. MD, DM (Lakshmi Hospital, Palakkad); A. George Koshy. MD, DM(Government Medical College Hospital, Trivandrum); EappenPunnose. MD, DM (MOSCMedical College, Ernakulam); Johny Joseph. MD, DM (Caritas Hospital, Kottayam);Rachel Daniel. MD, DM (NS Memorial Institute of Medical Sciences, Kollam);Asokan Nambiar. MD, DM (Baby Memorial Hospital, Calicut); C.G. Sajeev. MD, DM,PhD (Calicut Medical College Hospital, Calicut); Stigi Joseph. MD, DM (LittleFlower Hospital, Angamally); Koshy Eapen. MD, DM (Samaritan Hospital,Ernakulam); Raghu Ram. MD, DM (Alshifa Hospital, Perinthalmanna); Cibu Mathew.MD, DM (Government Medical College Hospital, Trichur); Ali Faizal. MD, DM(MIMS- Hearts Malabar Cardiac Centre, Kottakal); Biju Issac. MD, DM (MarianMedical Centre, Palai); Sujay Renga. MD, DM (Bishop Benzigar Hospital, Kollam),Jaideep Menon. MD, DM (SN Hospital, Manjali); D. Harikrishna. MD, DM (PVSHospital, Ernakulam); K. Suresh. MD, DM (S K Hospital, Edapazhinji,Trivandrum);Tiny Nair. MD, DM (PRS Hospital, Karamana, Trivandrum); S.S. Susanth. MD, DM(Bharat Hospital, Kottayam); R. Anil Kumar. MD, DM (Aster Medicity, Kochi);T.P. Abilash. MD, DM (Gokulam Heart Foundation, Thiruvananthapuam); P.Sreekala. MD, DM (SIMS Hospital, Kollam); E. Rajeev. MD, DM (MES MedicalCollege Hospital, Perinthalmanna); Arun Raj. MD, DM (General Hospital., Trivandrum); Ramdas Naik. MD, DM (Rajagiri, Aluva); Rajalekshmi. MD, DM (SUTHospital, Trivandrum); Anoop Gopinath. MD, DM (Welcare Hospital, Palakkad); R.Binu. MD, DM (Upasana Hospital, Kollam); Jossy Chacko. MD, DM (Holy CrossHospital, Kottiyam); P T. Iqbal. MD, DM (Daya General Hospital and surgicalcentre, Thrissur); N M Sudhir. MD, DM (KVM Hospital, Alappuzha); MadhuSreedharan. MD, DM (NIMS Hospital, Neyyattinkara); N. Balakrishnan. MD, DM (Sunrise Hospital,Ernakulam); Muhammed Musthaffa. MD, DM (Metro International Cardiac Centre,Calicut); B. Jayakumar. MD, DM (Thankam Hospital, Palakkad); Sheeba George. MD,DM (Jubilee Hospital, Trivandrum); Anand Kumar. MD, DM (Lakeshore Hospital,Ernakulam); Thomas Mathew. MD, DM (MGM Muthoot Medical Centre, Kozhencherry);V.K. Pramod. MD, DM (Aswini Hospital,Trissur); Muhammed Shaloob. MD, DM (Leo Hospital, Wayanad); PP Mohanan. MD, DM(Westfort Hi Tech Hospital); Madhu Paulose Chandy. MD, DM (St. Gregarious CardiovascularCentre, Parumala); K.R Vinod. MD, DM (AKG Memorial Hospital, Kannur); V.Krishna Kumar. MD, DM (Ananthapuri Hospitals and Research Institute, Trivandrum);Shifas M Babu. MD, DM (Ananthapuri Hospitals and Research Institute, Trivandrum);Anand M Pillai. MD, DM (Ananthapuri Hospitals and Research Institute, Trivandrum);Karuana Das. MD, DM (Government Medical College Hospital, Trichur); Z.SajanAhamad. MD, DM (Pushpagiri Medical College, Thiruvalla); Jabeen Azeem. MD(Lakshmi Hospital, Palakkad) S. Viswanatha Kartik. MD (Sree Chitra Tirunallnstitute for Medical Sciences and Technology, Trivandrum) Pramod Mathew. MBBS(Ananthapuri Hospitals and Research Institute, Trivandrum). Veena Felix. MD(Government Medical College Hospital, Trivandrum)

Contributors CGB conceptualised the study and drafted the manuscript. GYHL, JLA, SM and SB contributed in the design and conduct of the study and were involved in the preparation of the manuscript. NN, JA, AGK, VK, RG, AN, UG, GZ, NKU, SCG, SN, AR, KVV, AMP and RD contributed towards planning, designing and implementation of the study. All authors have read and approved the manuscript.

Funding The work was supported by the Kerala Chapter of Cardiological Society of India through a one-time research grant No. CSI/IEC/2017.

Map disclaimer The depiction ofboundaries on the map(s) in this article do not imply the expression of anyopinion whatsoever on the part of BMJ (or any member of its group) concerningthe legal status of any country, territory, jurisdiction or area or of itsauthorities. The map(s) are provided without any warranty of any kind, eitherexpress or implied.

Competing interests None declared.

Patient consent for publication Obtained.

Ethics approval The study was approved by the following ethics committees: Institutional Ethics Committee, Ananthapuri Hospitals and Research Institute; Institutional Ethics Committee, Sree Chitra Tirunal Institute of Medical Sciences and Technology; Ethics Committee, Lisie Heart Institute; Institutional Ethics Committee, Amrita Institute of Medical Sciences; Human Ethics Committee, Government Medical College, Trivandrum; Institutional Ethics Committee, Carithas Hospital, Kottayam; Institutional Ethics Committee, Sree Narayana Institute of Medical Sciences, Institutional Ethics Committee, Government Medical College, Calicut as well as by the Independent Ethics Committee of CSI-K.

Provenance and peer review Not commissioned; externally peer reviewed.

Data sharing statement The data are owned by the Cardiological Society of IndiaKerala Chapter and may be available after the study has been completed.

Open access This is an open access article distributed in accordance with the Creative Commons Attribution Non Commercial (CC BY-NC 4.0) license, which permits others to distribute, remix, adapt, build upon this work non-commercially, and license their derivative works on different terms, provided the original work is properly cited, appropriate credit is given, any changes made indicated, and the use is non-commercial. See: http://creativecommons.org/licenses/by-nc/4.0/.

\section{REFERENCES}

1. Benjamin EJ, Wolf PA, D'Agostino RB, et al. Impact of atrial fibrillation on the risk of death: the Framingham Heart Study. Circulation 1998;98:946-52.

2. Wolf PA, Abbott RD, Kannel WB. Atrial fibrillation as an independent risk factor for stroke: the Framingham Study. Stroke 1991;22:983-8.

3. Lip GYH, Freedman B, De Caterina R, et al. Stroke prevention in atrial fibrillation: Past, present and future. Thromb Haemost 2017;117:1230-9.

4. Bai Y, Wang YL, Shantsila A, et al. The global burden of atrial fibrillation and stroke: a systematic review of the clinical epidemiology of atrial fibrillation in Asia. Chest 2017;152:810-20.

5. Soman CR, Kutty VR, Safraj S, et al. All-cause mortality and cardiovascular mortality in Kerala state of India: results from a 5-year follow-up of 161,942 rural community dwelling adults. Asia Pac J Public Health 2011;23:896-903. 
6. Thankappan KR, Shah B, Mathur P, et al. Risk factor profile for chronic non-communicable diseases: results of a community-based study in Kerala, India. Indian J Med Res 2010;131:53-63.

7. Vora A, Kapoor A, Nair M, et al. Clinical presentation, management, and outcomes in the Indian Heart Rhythm Society-Atrial Fibrillation (IHRS-AF) registry. Indian Heart J 2017;69:43-7.

8. Kirchhof P, Benussi S, Kotecha D, et al. 2016 ESC Guidelines for the management of atrial fibrillation developed in collaboration with EACTS. Eur Heart J 2016;;37:2893-962.

9. Population of Kerala. 2018. http://indiapopulation2018.in/populationof-kerala-2018.html

10. Lip GY, Nieuwlaat R, Pisters R, et al. Refining clinical risk stratification for predicting stroke and thromboembolism in atrial fibrillation using a novel risk factor-based approach: the euro heart survey on atrial fibrillation. Chest 2010;137:263-72.

11. Pisters R, Lane DA, Nieuwlaat R, et al. A novel user-friendly score (HAS-BLED) to assess 1-year risk of major bleeding in patients with atrial fibrillation: the Euro Heart Survey. Chest 2010;138:1093-100.

12. Lauritsen JM, Bruus ME. A comprehensive tool for validated entry and documentation of data. The EpiData Association, Odense Denmark. 2004;2003.

13. Team RC R: A language and environment for statistical computing. Vienna, Austria: R Foundation for Statistical Computing. http://www. R-project.org/

14. Levey AS, Eckardt KU, Tsukamoto Y, et al. Definition and classification of chronic kidney disease: a position statement from Kidney Disease: Improving Global Outcomes (KDIGO). Kidney Int 2005;67:2089-100.

15. Lip GY, Laroche C, loachim PM, et al. Prognosis and treatment of atrial fibrillation patients by European cardiologists: one year followup of the EURObservational Research Programme-Atrial Fibrillation General Registry Pilot Phase (EORP-AF Pilot registry). Eur Heart $J$ 2014;35:3365-76.

16. Narasimhan C, Verma JS, Ravi Kishore AG, et al. Cardiovascular risk profile and management of atrial fibrillation in India: Real world data from RealiseAF survey. Indian Heart J 2016;68:663-70.

17. Alam M, Bandeali SJ, Shahzad SA, et al. Real-life global survey evaluating patients with atrial fibrillation (REALISE-AF): results of an international observational registry. Expert Rev Cardiovasc Ther 2012;10:283-91.

18. Oldgren J, Healey JS, Ezekowitz M, et al. Variations in etiology and management of atrial fibrillation in a prospective registry of 15,400 emergency department patients in 46 countries: the RE-LY AF registry. Circulation 2014;113.
19. Lip GY, Al-Khatib SM, Cosio FG, et al. Contemporary management of atrial fibrillation: what can clinical registries tell us about stroke prevention and current therapeutic approaches? J Am Heart Assoc 2014;3:e001179.

20. Lip GY, Laroche C, Dan GA, et al. A prospective survey in European Society of Cardiology member countries of atrial fibrillation management: baseline results of EURObservational Research Programme Atrial Fibrillation (EORP-AF) Pilot General Registry. Europace 2014;16:308-19.

21. Kakkar AK, Mueller I, Bassand JP, et al. International longitudinal registry of patients with atrial fibrillation at risk of stroke: Global Anticoagulant Registry in the FIELD (GARFIELD). Am Heart $J$ 2012;163:13-19.

22. Piccini JP, Fraulo ES, Ansell JE, et al. Outcomes registry for better informed treatment of atrial fibrillation: rationale and design of ORBIT-AF. Am Heart J 2011;162:606-12.

23. Camm AJ, Breithardt G, Crijns $\mathrm{H}$, et al. Real-life observations of clinical outcomes with rhythm- and rate-control therapies for atrial fibrillation RECORDAF (Registry on Cardiac Rhythm Disorders Assessing the Control of Atrial Fibrillation). J Am Coll Cardiol 2011;58:493-501.

24. Chang SS, Dong JZ, Ma CS, et al. Current Status and Time Trends of Oral Anticoagulation Use Among Chinese Patients With Nonvalvular Atrial Fibrillation: The Chinese Atrial Fibrillation Registry Study. Stroke 2016;47:1803-10.

25. Hsu JC, Akao M, Abe M, et al. International Collaborative Partnership for the Study of Atrial Fibrillation (INTERAF): rationale, design, and initial descriptives. J Am Heart Assoc 2016;5:e004037.

26. Murphy A, Banerjee A, Breithardt G, et al. The World Heart Federation Roadmap for Nonvalvular Atrial Fibrillation. Glob Heart 2017;12:273-84.

27. Alpert JS. Atrial fibrillation: a growth industry in the 21st century. Eur Heart J 2000;21:1207-8.

28. Kannel WB, Benjamin EJ. Status of the epidemiology of atrial fibrillation. Med Clin North Am 2008;92:17-40.

29. Morillo CA, Banerjee A, Perel P, et al. Atrial fibrillation: the current epidemic. J Geriatr Cardiol 2017;14:195.

30. Deore R, Vora A. Epidemiology and risk factor for atrial fibrillation in India. J Prev Cardiol 2014;3:507.

31. Bahuleyan CG, Shifas Babu M. Need for National Atrial Fibrillation Registry in India. In: Chopra HK, Chandra P, Wander GS, Kumar V, et al, eds. Atrial Fibrillation Update: A Textbook of Cardiology. New Delhi: JP Medical Ltd, 2017. 